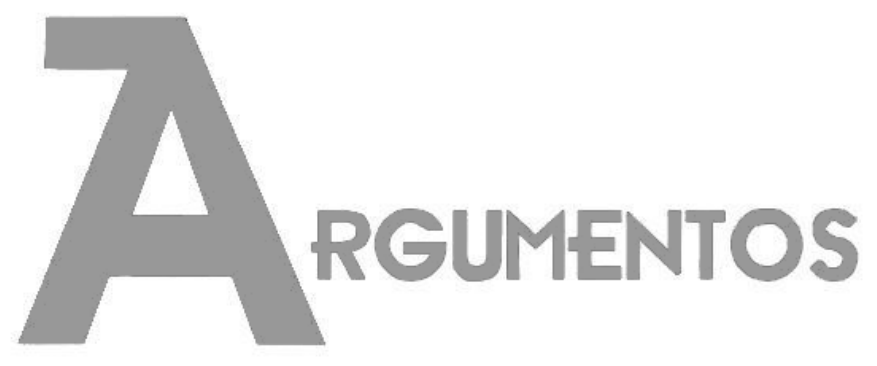

Vol. 17, n. 2, jul./dez. 2020 ISSN: 2527-2551 (online)

\title{
O Brasil e o passado dos Jogos Olímpicos Modernos: um vazio historiográfico
}

\author{
João Manuel Casquinha Malaia Santos ${ }^{1}$ \\ Sérgio Settani Giglio²
}

Recebido em: 29/04/2020

Aprovado em: 01/06/2020

\begin{abstract}
Resumo: Trabalhos de natureza historiográfica são importantes para se poder perceber os caminhos que a produção em pesquisa histórica sobre determinada temática tem trilhado. Nosso objetivo com este artigo é o de realizar um debate historiográfico sobre a pesquisa em história do esporte e, em particular, sobre o passado dos Jogos Olímpicos Modernos. 0 levantamento dos trabalhos foi realizado em bases internacionais e nacionais de pesquisa de livros, artigos, dissertações e teses. Os resultados nos mostram que, apesar de um crescimento nos estudos sobre o passado dos esportes, tanto no Brasil quanto no exterior, e sobre o passado dos Jogos Olímpicos Modernos na produção internacional, o Brasil ainda se ressente da falta de pesquisas sobre o passado da temática olímpica moderna.
\end{abstract}

Palavras-chave: Jogos Olímpicos Modernos; historiografia; pesquisa acadêmica; história dos esportes; esportes.

\section{Brasil y el pasado de los Juegos Olímpicos Modernos: un vacío historiográfico}

Resumen: Las obras de naturaleza historiográfica son importantes para poder percibir los caminos que ha tomado la producción en la investigación histórica sobre un tema determinado. Nuestro objetivo con este artículo es llevar a cabo un debate historiográfico sobre la investigación en la historia del deporte y, en particular, sobre el pasado de los Juegos Olímpicos modernos. La encuesta de los trabajos se realizó en bases internacionales y nacionales para la investigación de libros, artículos, disertaciones y tesis. Los resultados nos muestran que, a pesar de un aumento en los estudios sobre el pasado de los deportes, tanto en Brasil como en el

\footnotetext{
${ }^{1}$ Professor do Departamento de História, do Programa de Pós-Graduação em História e do Programa de Mestrado Profissional em Ensino de História da Universidade Federal de Santa Maria. E-mail: jmalaia@gmail.com. ORCID: https://orcid.org/0000-0001-7154-3860.

2 Professor do Departamento de Educação Física e do Programa de Pós-Graduação em Educação Física da Universidade Estadual de Campinas. E-mail: sergio@fef.unicamp.br. ORCID: https://orcid.org/0000-00023190-0859.
} 
Dossiê | O Brasil e o passado dos Jogos Olímpicos Modernos: um vazio historiográfico (SANTOS, João Manuel Casquinha Malaia; GIGLIO, Sérgio Settani)

extranjero, y sobre el pasado de los Juegos Olímpicos Modernos en la producción internacional, Brasil todavía resiente la falta de investigación sobre el pasado de temática olímpica moderna.

Palabras clave: Juegos Olímpicos Modernos; historiografia; pesquisa academica; história de los deportes; deportes.

\section{Brazil and the past of the Modern Olympic Games: a historiographic void}

Abstract: Works of a historiographical nature are important to be able to perceive the paths that the production in historical research on a certain theme has taken. Our aim with this article is to conduct a historiographical debate about research in sports history and, in particular, about the past of the Modern Olympic Games. The survey of the works was carried out on international and national bases for researching books, articles, dissertations and theses. The results show us that, despite an increase in studies on the past of sports, both in Brazil and abroad, and on the past of the Modern Olympic Games in international production, Brazil still resents the lack of research on the past of modern Olympic themed.

Keywords: Modern Olympic Games; historiography; academic research; sports history; sports.

\section{Introdução}

Uma das temáticas menos abordadas nos estudos de história do esporte são os debates historiográficos. Estudos sobre a historiografia de uma determinada temática são importantes não apenas para se fazer um levantamento sobre o que já se escreveu sobre este tema, mas por também por identificar lacunas de pesquisa e perspectivas para que os estudos avancem em qualidade e em contribuição para a área em questão. Este é o principal objetivo deste trabalho, ao realizar um debate historiográfico sobre história do esporte e, mais especificamente, sobre a produção historiográfica brasileira sobre Jogos Olímpicos.

Um dos pontos importantes a serem abordados em um trabalho desta natureza para uma revista de História ou de Ciências Sociais é justamente pensar na situação atual da pesquisa em história do esporte em termos de contribuição para as diferentes áreas do conhecimento de uma forma mais ampla. No presente dossiê, que busca refletir sobre aspectos ligados aos Jogos Olímpicos, cremos ser necessário um levantamento historiográfico sobre este fenômeno no Brasil. Procuraremos perceber qual a relevância da temática da história do esporte na produção acadêmica brasileira, quais as áreas que mais se interessam por esta temática, além de notar, não só de maneira quantitativa mas também qualitativa, os caminhos já traçados pela pesquisa nacional e aqueles que ainda podem ser percorridos.

Para isto, antes de adentrarmos nas discussões nacionais, apresentaremos um breve panorama das discussões sobre história do esporte nos principais meios 
Dossiê | O Brasil e o passado dos Jogos Olímpicos Modernos: um vazio historiográfico (SANTOS, João Manuel Casquinha Malaia; GIGLIO, Sérgio Settani)

acadêmicos internacionais e sobre as mais recentes produções acadêmicas sobre a história dos Jogos Olímpicos tanto nas revistas acadêmicas especializadas em história do esporte, quanto em algumas das principais revistas de História do Mundo. Tal panorama poderá nos mostrar o contexto historiográfico atual internacional sobre a temática e nos dar elementos para termos uma melhor perspectiva da produção nacional.

O artigo inicia apresentando este panorama historiográfico internacional, para depois abordar a situação nacional. Após estas análises, mostramos os caminhos já percorridos no Brasil à luz da produção internacional e as questões que se apresentam como maiores desafios para a escrita da história dos Jogos Olímpicos no Brasil.

\section{A História do Esporte como campo de pesquisa: discussões internacionais}

A pesquisa no campo de História do Esporte não é recente. Existem alguns bons artigos publicados em língua portuguesa que dão conta da evolução deste campo de estudos, como por exemplo, o estudo de Victor Melo e Rafael Fortes (2010), que apresenta um panorama dos estudos de história do esporte tanto no Brasil, quanto em outros países. Os autores apontam que, fora do Brasil, o campo começou a se estruturar desde a década de 1960. Além disso, são citadas inúmeras revistas acadêmicas especializadas na temática: European Studies in Sports History, International Journal of the History of Sport, Sport History Review, Journal of Sport History, Sport in History, Sporting Traditions e Materiales para la Historia del Deporte. Além dessas, são citadas duas revistas especializadas na temática olímpica, sendo uma delas voltada para as manifestações "esportivas" na Antiguidade (Nikephoros) e a outra voltada para estudos olímpicos da chamada Era Moderna, o Journal of Olympic History, publicada pela International Society of Olympic Historians.

Estas publicações atestam uma produção historiográfica crescente desde os anos 1970 até a atualidade. No entanto, segundo alguns autores, o campo da história do esporte estaria passando por um processo de "guetificação" e teria pouco a oferecer para o campo mais amplo da pesquisa histórica, justamente por se multiplicarem as revistas especializadas. Wiggins e Mason (2005), por exemplo, afirmam que a história do esporte segue sendo vista como área de menor valor no meio acadêmico, tendo 
Dossiê | O Brasil e o passado dos Jogos Olímpicos Modernos: um vazio historiográfico (SANTOS, João Manuel Casquinha Malaia; GIGLIO, Sérgio Settani)

pouco prestígio e reconhecimento, quer nos departamentos de História, quer nos de Educação Física.

Esta foi também a opinião de Paul Ward, professor do Departamento de História, Inglês, Linguagens e Mídia da Universidade de Huddersfield (Inglaterra). Ward (2013) publicou um ensaio em que o mesmo denominou de polêmico, no International Journal of the History of Sport, que perguntava no título se os historiadores do mainstream deveriam "jogar" com os historiadores do esporte. Apesar de o autor reconhecer a importância do fenômeno (principalmente para os estudos de identidade) e até mesmo ter dedicado um capítulo inteiro de uma de suas principais obras (Britishness since 1870, de 2004), o mesmo tece severas críticas quanto à qualidade da maioria dos trabalhos produzidos.

Ward afirma que, basicamente, são três os problemas apresentados: a baixa qualidade dos artigos sobre história dos esporte em revistas ou de dossiês específicos; material produzido muitas vezes é uma coleção de dados e de curiosidades, trazendo pouco avanço à pesquisa em História; e a maioria dos historiadores do esporte projetam o presente do esporte para a observação do passado do fenômeno. Para este autor, o esporte não deveria ser separado em análise de outros fenômenos da cultura popular e de massas. No entanto, conclui que sim, os historiadores mainstream deveriam dialogar com a história do esporte e ao ignorarem este fenômeno, poderiam assumir uma atitude de "esnobe acadêmico" (WARD, 2013, p. 12).

$\mathrm{O}$ artigo de Ward gerou uma resposta quase imediata de parte de Matthew L. McDowell, professor da School of Humanities, da Universidade de Glasgow (Escócia), no mesmo número da International Journal of the History of Sport. McDowell (2013) afirma que os argumentos de Ward (2013) são, no mínimo, fracos. Aponta que Ward não citou nominalmente os trabalhos que dizia serem fracos e que ignorou estudos que romperam a barreira acadêmica do campo da história do esporte, passando a ser de interesse tanto na pesquisa histórica mais ampla, quanto para um público mais diversificado. McDowell (2013) cita como dois exemplos deste tipo de trabalho os livros Mud, Sweat and Beers: A Cultural History of Sport and Alcohol de Tony Collins e Wray Vamplew (2002) e Darts in England 1900- 1939: A Social History, de Patrick Chaplin (2009).

McDowell (2013) segue desmontando os argumentos de Ward (2013), mostrando 
Dossiê | O Brasil e o passado dos Jogos Olímpicos Modernos: um vazio historiográfico (SANTOS, João Manuel Casquinha Malaia; GIGLIO, Sérgio Settani)

que as publicações específicas de história do esporte são citadas por historiadores de outros campos e que estes periódicos atraem pesquisadores de outras áreas ampliando a possibilidade de abordagens interdisciplinares. Afirma também que Ward (2013) não define e nem especifica o que seria historiadores mainstream. No entanto, apresenta ao menos quatro revistas do que poderia ser considerado mainstream que já haviam publicado dossiês temáticos sobre história do esporte: Journal of Contemporary History $^{3}$; The London Journal ${ }^{4}$; Media History ${ }^{5}$; e Journal of Historical Sociology ${ }^{6}$.

De 2013 até hoje, mais periódicos do chamado mainstream seguiram dando espaço para a temática da história do esporte. Foi o caso da revista Journal of Global History $^{7}$ e da Radical History ${ }^{8}$. Além disso, outras revistas que estão entre as de maior fator de impacto internacional na área de História publicam estudos sobre história do esporte, como a Nations and Nationalism (HOULIHAN, 2004; VACZI; BAIRNER; WHIGHAM, 2019) e a Comparative Studies in Society and History (MORRIS, 2000; BESNIER; GUINNESS; HANN; KOVAČ, 2018). Não resta dúvida de que alguns dos argumentos de Ward (2013) realmente são frágeis ao acusar a história do esporte de pouco diálogo com a história mainstream. No entanto, tanto Ward (2013) quanto McDowell (2013), concordam com o fato de existir uma necessidade constante dos trabalhos de história do esporte dialogarem mais com a área mais ampla da História, seja pela publicação de artigos em revistas de impacto da área, seja pela formulação de dossiês específicos para estas temáticas.

Mas, como estaria esta situação no Brasil?

\section{A História do Esporte no Brasil}

Não nos cabe aqui fazer uma recuperação da evolução do campo de pesquisas de história do esporte no Brasil. Este trabalho foi realizado no artigo já citado de Melo e Fortes (2010). Nosso objetivo aqui é problematizar a polêmica levantada por Ward (2013) e respondida por McDowell (2013), mas transpondo esta questão para o Brasil.

\footnotetext{
${ }^{3}$ 2003, v. 38, n. 3: Sport and Politics.

${ }^{4} 2009$, v. 34, n. 2: Sport in London.

${ }^{5}$ 2011, v. 17, n. 2: Sport and the Media in Ireland.

${ }^{6} 2011$, v. 24, n. 4: Sports and History.

7 2013, v. 8, n. 2: Sport: Transnationalism and Global History.

${ }^{8}$ 2016, v. 16, n. 2: Historicizing the Politics and Pleasure of Sport.
} 
Dossiê | O Brasil e o passado dos Jogos Olímpicos Modernos: um vazio historiográfico (SANTOS, João Manuel Casquinha Malaia; GIGLIO, Sérgio Settani)

A ideia é pensar como este campo temático específico dialoga com o campo da História mais geral, qual sua inserção nas principais revistas do país e de que maneira historiadores ligados a departamentos de História atuam junto à investigação em história do esporte.

Em relação ao campo de estudos da história do esporte, a situação no Brasil tem uma situação peculiar. Desde o início dos anos 2000, há um simpósio temático específico sobre História do Esporte nos simpósios da Associação Nacional de História (ANPUH). Para ser mais específico, desde 2003, com a aprovação do simpósio “História do Esporte e do Lazer no Brasil" ou "História da Educação Física e do Esporte" (MELO, 2016). Desde então, uma produção que crescia quantitativa e qualitativamente desde os primeiros encontros da ANPUH, consolidou-se com um espaço próprio para o debate de pesquisas nesta temática.

Nas universidades, principalmente nos cursos de graduação e pós-graduação de Educação Física e História, o número de profissionais envolvidos com a temática e o número de alunos que se interessam por fazer trabalhos de conclusão, dissertações e teses sobre História do Esporte também apresenta um significativo crescimento. Esta situação é mais presente na área da Educação Física, de onde surgiram os primeiros pesquisadores envolvidos com a história do esporte.

Existem cinco grupos de pesquisas cadastrados no Diretório de Grupos de Pesquisas no Brasil que se utilizam da palavra olímpicos como parte do nome do grupo. Quatro deles indicam como áreas predominantes as Ciências Biológicas e a Educação Física e um as Ciências Humanas e a Psicologia. Embora o Grupo de Estudos Olímpicos liderado pela professora Katia Rubio indique as Ciências Humanas e a Psicologia como áreas predominantes ${ }^{9}$, durante muito tempo esteve sediado na Escola de Educação Física e Esporte da USP10. Esse grupo desenvolve há décadas a pesquisa "Memórias Olímpicas por Atletas Olímpicos" (RUBIO, 2014). Na Universidade Federal do Rio Grande do Sul (UFRGS) há o Centro de Estudos Olímpicos e Paralímpicos liderado por Alberto Reinaldo Reppold Filho e Alcides Vieira Costa ${ }^{11}$. Na Pontifícia Universidade Católica do

\footnotetext{
${ }^{9} \mathrm{O}$ grupo foi cadastrado em 2002 no Diretório dos Grupos de Pesquisas, porém sua fundação é anterior a esta data. Disponível em: http://dgp.cnpq.br/dgp/espelhogrupo/4542. Acesso em 20 de abril de 2020.

${ }^{10}$ Atualmente a professora Katia Rubio leciona na Faculdade de Educação da Universidade de São Paulo.

${ }^{11}$ Cadastrado desde 2000. Disponível em: http://dgp.cnpq.br/dgp/espelhogrupo/15561. Acesso em 20 de abril de 2020.
} 
Dossiê | O Brasil e o passado dos Jogos Olímpicos Modernos: um vazio historiográfico (SANTOS, João Manuel Casquinha Malaia; GIGLIO, Sérgio Settani)

Rio Grande do Sul (PUCRS) está sediado o Grupo de Pesquisa em Estudos Olímpicos liderado por Nelson Schneider Todt e Alessandra Maria Scarton ${ }^{12}$. Na Universidade Federal do Espírito Santo, Otávio Guimarães Tavares da Silva lidera o grupo ARETE Centro de Estudos Olímpicos ${ }^{13}$. O grupo mais recente cadastrado é da Universidade Federal de Sergipe (UFS) liderado por Marcelo de Castro Haiachi e Ailton Fernando Santana de Oliveira ${ }^{14}$. No entanto, a temática também vem ganhando destaque nos departamentos de História, mas ainda sem contar com um Grupo de Pesquisa focado especificamente nesse assunto.

Uma pesquisa no Portal de Teses e dissertações da Capes com a palavra-chave "esporte" mostra que entre 1992 e 1999 foram realizados apenas quatro trabalhos na área de História. Entre os anos 2000 e 2009 o número cresceu para 35 e entre 2010 e 2019 para 89 teses ou dissertações. Estes trabalhos foram distribuídos por diversos programas de pós-graduação em História do Brasil, com destaque para programas na Universidade Federal do Rio de Janeiro (20), Universidade de São Paulo (14), Pontifícia Universidade Católica de São Paulo (12), Universidade Federal Fluminense (9), Universidade Federal de Minas Gerais (8) e Universidade Federal do Paraná (7).

Sem dúvida, há uma temática que prevalece nas pesquisas realizadas nos programas de pós-graduação em História. A maioria destes trabalhos é sobre futebol (73, ou $58,8 \%)$, seguido de pesquisas sobre o esporte em geral $(17$, ou $12,1 \%)$. A modalidade específica que aparece a seguir ao futebol é a capoeira ( 3 trabalhos, ou $2,4 \%$ ), seguido do boxe ( 2 trabalhos, ou 1,6\%). A maioria das modalidades estudadas têm apenas uma pesquisa cada, como voleibol, basquetebol, surfe, skate, ciclismo, rúgbi e tae-kwon-do.

Outro bom indicador da presença crescente da temática da história do esporte no meio acadêmico é a presença de dossiês temáticos em revistas com consideradas de boa qualificação pela Capes (Qualis A1, A2, B1 e B2). São exemplos desses dossiês as publicações da revista Estudos Históricos (1999 - Esportes e Lazer; e 2019 - Futebol e

\footnotetext{
${ }^{12}$ Cadastrado desde 2002. Disponível em: http://dgp.cnpq.br/dgp/espelhogrupo/39082. Acesso em 20 de abril de 2020.

${ }^{13}$ Cadastrado desde 2011. Disponível em: http://dgp.cnpq.br/dgp/espelhogrupo/547958. Acesso em 20 de abril de 2020.

${ }^{14}$ Cadastrado desde 2018. Disponível em: http://dgp.cnpq.br/dgp/espelhogrupo/345350. Acesso em 20 de abril de 2020.
} 
Dossiê | O Brasil e o passado dos Jogos Olímpicos Modernos: um vazio historiográfico (SANTOS, João Manuel Casquinha Malaia; GIGLIO, Sérgio Settani)

Política), da Revista de História da USP (2010 - História e Futebol), da revista Tempo (2013 - História do Esporte), da revista Vozes, Pretérito \& Devir (2016 - História do Esporte) e da História Questões e Debates (2020 - História do Esporte). Além disso, praticamente todas as revistas bem classificadas do Brasil já publicaram artigos sobre história do esporte. Para além das já citadas, podemos encontrar artigos em números da Revista Brasileira de História, Topoi, Anos 90, Revista História (São Paulo) e Tempo e Argumento.

Vale ressaltar ainda que o Brasil também possui uma publicação específica nesta área. A revista Recorde: Revista de História do Esporte e do Lazer é um esforço de trabalho do grupo de pesquisa Sport: Laboratório de História do Esporte e do Lazer, vinculado ao Programa de Pós-Graduação em História Comparada da UFRJ. A Recorde é publicada desde 2008, tendo publicado já 24 números.

Podemos argumentar que a presença do esporte como temática da área de pesquisa em História possui uma situação que se consolida com o tempo. As críticas de Ward (2013) podem ser em parte recebidas aqui no Brasil. No entanto, é notório o esforço dos pesquisadores que se dedicam à história do esporte de estabelecer presença e espaço crescente nos fóruns de discussão da pesquisa histórica.

Mas, e em relação aos estudos dos Jogos Olímpicos? Qual a situação desta temática específica dentro da pesquisa em história do esporte, tanto no Brasil, quanto em um contexto internacional?

\section{Estudos internacionais sobre história dos Jogos Olímpicos}

O avanço nas pesquisas nos países de língua inglesa (principalmente Austrália, Estados Unidos e Reino Unido) e sua materialização com a profusão de revistas acadêmicas nos mostra não só a pujança da produção acadêmica sobre esportes, mas principalmente sobre Jogos Olímpicos. As três principais publicações de história do esporte no mundo publicaram centenas de trabalhos sobre os Jogos. A Sport in History, o International Journal of the History of Sport e o Journal of Sport History publicaram artigos sobre os Jogos Olímpicos abordando diversas temáticas como estudos de política interna dos países, de relações internacionais, estudos sobre minorias raciais, gênero, aspectos econômicos, cobertura dos meios de comunicação a determinados eventos, o 
Dossiê | O Brasil e o passado dos Jogos Olímpicos Modernos: um vazio historiográfico (SANTOS, João Manuel Casquinha Malaia; GIGLIO, Sérgio Settani)

Movimento Olímpico, doping, obre legados, aspectos econômicos, questões de identidade nacional, de memória, patrimônio, de exilados políticos, além de outras temáticas.

Além desta significativa produção sobre o passado dos Jogos Olímpicos nas principais revistas de histórias do esporte, artigos sobre o fenômeno olímpico também aparece em algumas das principais revistas de História. Por exemplo, há o artigo The republic of consumption at the Olympic Games: globalization, Americanization, and Californization de Mark Dyreson (2013), publicado no dossiê sobre esportes do Journal of Global History. Além deste, a revista Nations and Nationalism já publicou dois artigos sobre esta temática: Public Opinion, National Integration and National Identity in Spain: The Case of the Barcelona Olympic Games, de John Hargreaves e Manuel Garcia Ferrando (2004) e Narratives of the nation in the Olympic opening ceremonies: comparative analysis of Beijing 2008 and London 2012, de Jongsoo Lee Hyunsun Yoon (2017).

Há também uma extensa gama de livros sobre a história dos Jogos Olímpicos, tanto na Europa, quanto nos Estados Unidos. No caso europeu, tal historiografia sobre Jogos Olímpicos foi abordada, ao lado do futebol, como o tema de maior destaque de pesquisa, causando inclusive uma alarmante ignorância sobre outras modalidades esportivas e sobre outros fenômenos ligados ao esporte (YOUNG; HILBRENNER; TOMLINSON, 2011). No caso da França, os Jogos Olímpicos estão entre os temas de maior destaque nos estudos da história do esporte daquele país, como atesta Terret (2011).

Já nos EUA, Barney (2014) aponta que apesar da projeção e durabilidade do evento, a maior parte da produção sobre o passado do movimento olímpico havia sido escrita por jornalistas e colecionadores e sequer pode ser chamada de uma historiografia dos Jogos. No entanto, novos historiadores vêm se debruçando sobre o tema, principalmente por meios de investigações sobre aspectos políticos, comercialização do evento e com temas relacionados a raça, etnicidade e gênero, sobre os eventos sediados nos EUA e sobre escândalos relacionados à conquista da organização dos Jogos. O trabalho de Barney traz uma extensa lista de artigos, capítulos de livros e livros sobre as temáticas citadas e é uma fonte valiosa de consulta sobre a produção norte-americana do passado movimento olímpico produzida nos últimos 30 
Dossiê | O Brasil e o passado dos Jogos Olímpicos Modernos: um vazio historiográfico (SANTOS, João Manuel Casquinha Malaia; GIGLIO, Sérgio Settani)

anos.

Um dos trabalhos fundamentais sobre Jogos Olímpicos foi produzido por Allen Guttmann (1992). Em sua obra The Olympics: A History of the Modern Games, o autor define a história dos Jogos Olímpicos como uma narrativa complexa que conjuga feitos da elite esportiva com questões políticas e disputas mesquinhas. A pesquisa em longa duração de Guttmann, apesar de bastante panorâmica, inspirou outros autores a se aprofundarem em temáticas deixadas em aberto pelo autor.

Foi o caso de Helen Jefferson Lenskyj (2013), que se aprofundou na temática das relações de gênero em sua obra Gender Politics and the Olympic Industry. Helen Lenskyj é uma das principais pesquisadoras sobre Jogos Olímpicos do mundo. Além deste livro específico sobre gênero, a autora editou uma das mais importantes obras dos últimos anos sobre estudos olímpicos juntamente com Stephen Wagg. Trata-se do livro The Palgrave Handbook of Olympic Studies (LENSKYJ; WAGG, 2012), um trabalho com uma perspectiva crítica sobre vários temas sócio-políticos tanto do passado, quanto contemporâneos dos Jogos Olímpicos.

A última sessão do livro tem uma interessante discussão entre Lenskyj e lan Henry (autor que colabora com um capítulo no livro) sobre o balanço final dos Jogos Olímpicos enquanto fenômeno social. Para Henry (2012), apesar de ser um fenômeno imperfeito, e analisando os prós e contras a partir da perspectiva cultural, política, econômica, social, ambiental e esportiva, os Jogos são um evento com saldo positivo, podendo espalhar ao mundo uma mensagem de união e engajamento intercultural. Já para Lenskyj (2012), ao perpetuar uma mitologia esportiva de que os Jogos Olímpicos e os esportes são uma espécie de "bala mágica" que pode resolver qualquer problema, o Comitê Olímpico Internacional (COI) falhou em promover uma liderança responsável e transparente ao mundo.

O livro traz também alguns capítulos com contribuições importantes para as abordagens críticas da história dos Jogos Olímpicos. Há exemplos de estudos de casos sobre eventos passados, como o capítulo específico sobre a abordagem histórica dos Jogos, escrito por Toby C. Rider e Kevin B. Wamsley (2012). Os autores atestam que os Jogos modernos assentam em dois mitos falaciosos que seriam a promoção da paz e a não discriminação. Mostram, por exemplo, que os Jogos reforçam o controle masculino dos aspectos políticos, econômicos e culturais da competição, celebrando as 
Dossiê | O Brasil e o passado dos Jogos Olímpicos Modernos: um vazio historiográfico (SANTOS, João Manuel Casquinha Malaia; GIGLIO, Sérgio Settani)

capacidades físicas, a força e a velocidade dos atletas masculinos. Além disso, procuram mostrar que a história dos Jogos Olímpicos tem numerosos exemplos de que esta competição tem se mostrado como um fórum político e que os mitos falaciosos são perpetuados por diversos meios e pela mídia.

Poderíamos aqui seguir citando uma série de obras importantes e suas principais contribuições. No entanto, isto escapa do objetivo deste trabalho. O que nos interessa mostrar é como se encontra a produção historiográfica sobre os Jogos Olímpicos. Cada vez mais fugindo de uma história laudatória, cronológica e de engrandecimento dos Jogos Olímpicos, a produção internacional vêm se mostrando cada vez mais crítica, adentrando questões de gênero, raça, doping, corrupção, conflitos políticos e um sem número de questões que nos permitem cada vez mais compreender as inúmeras nuances do movimento olímpico e de tudo que está ao seu redor, problematizando as narrativas celebratórias e de certo modo heroicas produzidas pelo próprio $\mathrm{CO}$ e seus admiradores.

E como andam os estudos da história do Jogos Olímpicos na academia brasileira? Como os pesquisadores brasileiros estão contribuindo para uma compreensão mais crítica e abrangente do passado dos Jogos Olímpicos da era moderna?

\section{A história dos Jogos Olímpicos no Brasil: percepções das pesquisas}

O Brasil tem uma longa história nos Jogos Olímpicos. Não apenas em relação à participação de atletas, com a primeira acontecendo nos Jogos de 1920, em Antuérpia, Bélgica, a oitava edição do evento. Também há uma história relativa à organização de eventos com anuência do COI, como os Jogos Sul-Americanos de 1922, ou mesmo os Jogos Pan-Americanos (1963 e 2007) e os próprios Jogos Olímpicos, em 2016, no Rio de Janeiro. Além disso, vários dirigentes esportivos foram membros efetivos do COI, como Raul do Rio Branco (1913 a 1938), Arnaldo Guinle (1923 a 1961), Antonio do Prado Júnior (1938 a 1955) e João Havelange (1963 a 2012), apenas para citar alguns exemplos. Além disso, temos inúmeras histórias que poderiam nos dar uma visão crítica sobre os aspectos políticos, econômicos, sociais e culturais dos Jogos.

Apesar deste longo trajeto e suas inúmeras histórias, o número de trabalhos realizados no Brasil sobre temáticas que toquem os Jogos Olímpicos ou o COI é muito 
Dossiê | O Brasil e o passado dos Jogos Olímpicos Modernos: um vazio historiográfico (SANTOS, João Manuel Casquinha Malaia; GIGLIO, Sérgio Settani)

reduzido. Se pensarmos na produção historiográfica brasileira sobre as práticas esportivas, que vem se consolidando nos últimos anos, na intensa produção internacional sobre os Jogos e na presença deste fenômeno na história no Brasil, não deixa de surpreender este vazio historiográfico nas produções acadêmicas brasileiras sobre o passado dos Jogos Olímpicos.

Usando os mesmos parâmetros que usamos para mostrar o crescimento e consolidação da produção historiográfica nacional sobre esporte, fizemos uma análise qualitativa do que foi produzido em alguns dos principais fóruns de produção de pesquisa histórica no Brasil: os simpósios nacionais da ANPUH, as revistas científicas brasileiras de alto impacto, a Recorde (revista brasileira dedicada à história do esporte), a Olimpianos (revista recente brasileira dedicada aos estudos olímpicos e com alguns artigos sobre o passado dos Jogos), os programas de pós-graduação em História e também livros sobre o tema. Esta análise pode nos mostrar o quanto os estudos sobre Jogos Olímpicos estiveram pouco presentes nestes espaços. Além disso, pode nos mostrar um pouco melhor este vazio historiográfico a que nos estamos referindo.

Nos simpósios nacionais da ANPUH, apesar do número crescente de trabalhos apresentados nos eventos, a presença de trabalhos sobre os Jogos Olímpicos ou temas correlatos é muito pequena. Apenas três trabalhos foram identificados, no encontro nacional de 2017, talvez ainda um rescaldo do aumento do interesse no tema após os Jogos Rio 2016. São os trabalhos sobre a cobertura da imprensa brasileira dos Jogos Berlim 1936, de Elcio Loureiro Cornelsen (2017); o trabalho sobre João Havelange, realizado por Livia Gonçalves Magalhaes (2017); e trabalho apresentado de Sérgio Settani Giglio (2017) em que discutia "A busca pela definição de amadorismo (18941910)" dentro do movimento olímpico.

A pesquisa no Portal de Teses e Dissertações da Capes revela também a presença praticamente insignificante desta temática em trabalhos relacionadas à história dos Jogos Olímpicos. Dos 94 trabalhos encontrados, apenas dois trabalhos que referem-se a essa temática foram identificados em programas de pós-graduação em História. Um deles, o trabalho de Felipe Marta (2004), um mestrado defendido na PUC-SP, se debruça sobre uma modalidade específica ligada ao evento, tratando da história do Taekwondo em São Paulo, falando um pouco da relação da modalidade com sua presença nos Jogos Olímpicos, quando foi esporte demonstração em Seul (1988) e Barcelona (1992), e 
Dossiê | O Brasil e o passado dos Jogos Olímpicos Modernos: um vazio historiográfico (SANTOS, João Manuel Casquinha Malaia; GIGLIO, Sérgio Settani)

quando passou a ser esporte olímpico em Sidnei (2000). Já o mestrado de Karoline Teixeira (2008), defendido na Universidade Federal do Ceará, aborda a construção do corpo no filme Olympia, de Leni Riefenstahl, película oficial do governo alemão dos Jogos de Berlim (1936). Em um montante de quase uma centena de trabalhos, nota-se que esta não é uma temática que despertasse a atenção de um conjunto significativo de pesquisadores e orientadores.

Em outras áreas, também não foi identificado um número significativo de trabalhos sobre o passado dos Jogos Olímpicos. Alguns deles abordam diretamente algum evento do Jogos Olímpicos e foram realizados em programas de pós-graduação nas áreas de Educação Física, Esporte e Ciências do Movimento (LICO, 2007; SANTOS, 2011; ROSINA, 2018). Também nestas áreas, há pesquisas sobre a participação de atletas brasileiros ou da história brasileira das modalidades nos eventos olímpicos (GIGLIO, 2013, MADURO, 1999; MARTINI, 2013; MIRAGAYA, 2006; NUNES, 2011; SCHIAVON, 2009; SOUZA, 2007) ou sobre histórias da participação do Brasil no Movimento Olímpico (LEMOS, 2008; NETO, 1999). Há também trabalhos realizados em programas de pós-graduação da área de Comunicação (MONTANHA, 2014 e 2018), de Educação (NASCIMENTO, 2012) e de Relações Internacionais (VAREJÃO, 2006). As temáticas mais abordadas são questões ligadas à história das mulheres nos jogos (4) e questões políticas (3). Mesmo com uma presença de quase três centenas de dissertações de mestrado e teses de doutorado nas mais diversas áreas que abordam o passado das mais diversas manifestações esportivas, apenas 24 trabalhos (8\%) se debruçam sobre o passado dos Jogos Olímpicos.

Nas revistas científicas de boa qualificação na Capes, mesmo as que já publicaram alguns dossiês temáticos sobre história do esporte ou artigos sobre esta temática, nenhum artigo foi encontrado pensando no passado dos Jogos Olímpicos. Já na revista Recorde, os números de artigos publicados que abordem a questão olímpica é também pouco significativo. A Recorde já publicou 24 edições, com um total de 213 artigos. Deste total, apenas 13 artigos (6\%) se debruçam sobre os Jogos Olímpicos. Destes, apenas oito artigos são escritos por pesquisadores brasileiros. Na revista Olimpianos, dos 39 artigos publicados entre 2017 e abril de 2020, apenas seis tocam em elementos do passado dos Jogos Olímpicos.

A partir deste levantamento observado, pudemos mostrar o vazio historiográfico 
Dossiê | O Brasil e o passado dos Jogos Olímpicos Modernos: um vazio historiográfico (SANTOS, João Manuel Casquinha Malaia; GIGLIO, Sérgio Settani)

apontado por nós anteriormente no que se refere à produção de pesquisa no Brasil sobre o passado dos Jogos Olímpicos. Apesar de um levantamento preliminar, a pesquisa nas bases de dados levantadas pode nos dar segurança em afirmar que este é um campo de pesquisas ainda por explorar. No entanto, apesar do bom potencial analítico, vem sendo ainda negligenciado, a despeito do crescimento do campo de pesquisas em história do esporte.

\section{Considerações Finais}

Ao trazermos como objetivo deste trabalho realizar uma análise historiográfica sobre o passado dos Jogos Olímpicos no Brasil, nos deparamos com uma dificuldade inicial: a pouca produção brasileira nesta temática. A partir desta dificuldade inicial, nos propusemos a pensar em uma resposta que pudesse ilustrar o cenário da produção historiográfica internacional e nacional sobre esporte e sobre Jogos Olímpicos. Desta forma, pudemos compreender de que maneira os Jogos Olímpicos estão sendo tratados como um tema da história do esporte e os compassos e descompassos desta produção no mundo.

A produção internacional, principalmente em países de língua inglesa e francesa, aparece já consolidada não apenas com a produção de livros, artigos ou mesmo revistas especializadas nesta temática. Mas também com críticas a essa produção e com notáveis melhoras na qualidade nos últimos anos. Foi necessário percorrer um pouco da trajetória do campo de pesquisa em história do esporte no Brasil e fora dele com o intuito de dar uma ideia do crescimento e variedade de temáticas pesquisadas nos últimos anos. Os estudos do passado dos Jogos Olímpicos constituem um subcampo dentro deste campo maior da história do esporte. E fazia-se importante mostrar que, apesar do crescimento da história do esporte em termos internacionais e nacionais, o tema dos Jogos Olímpicos aparece pouco representada na pesquisa em história do esporte no Brasil.

Inicialmente, pensamos em colocar também estudos ligados aos Jogos Paralímpicos. Ao fim, decidimos por retirar este tema da análise, por um motivo simples: a ausência de trabalhos no Brasil sobre o passado dos Jogos Paralímpicos. Não estamos afirmando que trabalhos desta natureza não existem no Brasil. Mas apenas que nas 
Dossiê | O Brasil e o passado dos Jogos Olímpicos Modernos: um vazio historiográfico (SANTOS, João Manuel Casquinha Malaia; GIGLIO, Sérgio Settani)

bases de dados que nos dispusemos a fazer este levantamento, não encontramos nenhum trabalho sobre o passado dos Jogos Paralímpicos ou do Movimento Paralímpico. Nas revistas estrangeiras especializadas em história do esporte que citamos, a presença deste tipo de trabalho também é diminuta. No Brasil, este campo de pesquisa parece estar ainda totalmente em aberto.

A ideia foi trazer um panorama da produção internacional para poder mostrar este descompasso na produção brasileira e o vazio historiográfico ao qual nos referimos. Este vazio aponta diferentes caminhos de pesquisa. Estes caminhos podem passar por questões políticas, econômicas, culturais e sociais. Podem também esclarecer questões ligadas a gênero, classe e raça no passado dos Jogos Olímpicos e também com os Jogos Paralímpicos. O que se pode perceber é que há um caminho longo a ser percorrido.

Os trabalhos historiográficos nos dão a possibilidade de perceber lacunas e poder elencar alguns dos caminhos que podem ser trilhados. O que esperamos aqui é contribuir não apenas na reflexão sobre este vazio historiográfico, mas também estimular novos pesquisadores a colaborarem com os passos iniciais que ajudem a preencher este vazio. Temos esperança de que o próximo balanço historiográfico realizado sobre a produção de pesquisa sobre o passado do movimento olímpico no Brasil seja bastante diferente deste texto. Uma análise que mostre um quadro diferente em termos quantitativos e qualitativos, abordando de maneira crítica este passado e problematizando suas narrativas.

\section{Referências}

BARNEY, Robert. The United States in the Modern Olympic Movement: A Historiography. In: RIESSE, Steven (ed.). A Companion to American Sport History. West Sussex, Reino Unido: John Wiley \& Sons, 2014, p. 379-402.

BESNIER, Niko; GUINNESS, Daniel; HANN, Mark; KOVAČ, Uroš. Rethinking Masculinity in the Neoliberal Order: Cameroonian Footballers, Fijian Rugby Players, and Senegalese Wrestlers. Comparative Studies in Society and History. V. 60, n. 4, p. 839872, 2018.

CHAPLIN, P. Darts in England, 1900-1939: A Social History. Manchester/Reino Unido: Manchester University Press, 2009.

COLLINS, Tony; VAMPLEW, Wray. Mud, Sweat and Beers: A Cultural History of Sport and Alcohol. Oxford/Reino Unido: Berg, 2002. 
Dossiê | O Brasil e o passado dos Jogos Olímpicos Modernos: um vazio historiográfico (SANTOS, João Manuel Casquinha Malaia; GIGLIO, Sérgio Settani)

CORNELSEN, Elcio L. Os Jogos Olímpicos de Berlim e a cobertura da imprensa brasileira. In: SIMPÓSIO NACIONAL DE HISTÓRIA, 29, 2017, Brasília. Caderno de Resumos do XXIX Simpósio Nacional de História da ANPUH. Brasília: Universidade de Brasília, 2017, p. 1.072-1.073.

DYRESON, Mark. The republic of consumption at the Olympic Games: globalization, Americanization and Californization. Journal of Global History. V. 8, n. 2, p. 256-278, 2013.

GIGLIO, Sergio Settani. COI x FIFA: A História Política do Futebol nos Jogos Olímpicos. São Paulo, 2013. 518 f. Tese (Doutorado em Educação Física e Esporte) Universidade de São Paulo.

. A busca pela definição de amadorismo (1894-1910). In: SIMPÓSIO NACIONAL DE HISTÓRIA, 29, 2017, Brasília. Caderno de Resumos do XXIX Simpósio Nacional de História da ANPUH. Brasília: Universidade de Brasília, 2017, p. 1.082-1.083.

GUTTMANN, Allen. The Olympics: A History of the Modern Games. University of Illinois Press: Chicago (EUA), 1992.

HARGREAVES, John; FERRANDO, Manuel Garcia. Public Opinion, National Integration and National Identity in Spain: The Case of the Barcelona Olympic Games. Nations and Nationalism. V. 3, n. 1, p. 65-87, 2004.

HENRY, Ian. The Olympics: Why We Should Value Them. In: LENSKYJ, H. J.; WAGG, S. (eds.) The Palgrave Handbook of Olympic Studies. Hampshire/Reino Unido: Macmillan Publishers, 2012, p. 551-569.

HOULIHAN, Barrie. Sport, National Identity and Public Policy. Nations and Nationalism, V. 3, n. 1, p. 113-137, 2004.

LEMOS, Danilo L. R. A História Social do Movimento Olímpico Brasileiro no início do século XX. São Paulo, 2008, 81 f. Dissertação (Mestrado em Educação Física) Universidade de São Paulo.

LENSKYJ, Helen J. Gender Politics and the Olympic Industry. Hampshire/Reino Unido: Macmillan Publishers, 2013.

The Case against the Olympic Games: The Buck Stops with the IOC. In: LENSKYJ, H. J.; WAGG, S. (eds.) The Palgrave Handbook of Olympic Studies. Hampshire/Reino Unido: Macmillan Publishers, 2012, p. 570-579.

LENSKYJ, Helen J.; WAGG, Stephan. (eds.) The Palgrave Handbook of Olympic Studies. Hampshire/Reino Unido: Macmillan Publishers, 2012.

LICO, Flávio A. A. O Boicote aos Jogos Olímpicos de Moscou 1980: uma análise da reação do movimento olímpico brasileiro e internacional. São Paulo, 2007, 149 f. Dissertação (Mestrado em Educação Física) - Universidade de São Paulo.

MADURO, Luiz A. R. A História do Judô no Rio Grande do Sul: das primeiras manifestações aos Jogos Olímpicos de Atlanta. Porto Alegre, 1999. Dissertação (Mestrado em Ciências do Movimento Humano) - Universidade Federal do Rio Grande do Sul. 
Dossiê | O Brasil e o passado dos Jogos Olímpicos Modernos: um vazio historiográfico (SANTOS, João Manuel Casquinha Malaia; GIGLIO, Sérgio Settani)

MAGALHAES, Lívia G. O dono do jogo: João Havelange e a memória do esporte mundial. In: SIMPÓSIO NACIONAL DE HISTÓRIA, 29, 2017, Brasília. Caderno de Resumos do XXIX Simpósio Nacional de História da ANPUH. Brasília: Universidade de Brasília, 2017, p. 541-542.

MARTA, Felipe E. F. O Caminho dos Pés e das Mãos: Taekwondo. Arte Marcial, Esporte e a Colônia Coreana em São Paulo (1970-2000). São Paulo, 2004, 132 f. Dissertação (Mestrado em História) - Pontifícia Universidade Católica de São Paulo.

MARTINI, Sergio R. B. Memórias dos Atletas Olímpicos dos Clubes Sul-riograndenses. Porto Alegre, 2013. Dissertação (Mestrado em Ciências do Movimento Humano) - Universidade Federal do Rio Grande do Sul.

MCDOWELL, Matthew L. Sports History: Outside of the Mainstream? A Response to Ward's 'Last Man Picked'. The International Journal of the History of Sport. V. 30, n. 1, p. 14-22, 2013.

MELO, Victor A. O Trato do Esporte nos Simpósios da Associação Nacional de História. Recorde, V. 9, n. 1, p. 1- 17, 2016.

MELO, Victor A.; FORTES, Rafael. História do esporte: panorama e perspectivas. Fronteiras, V. 12, n. 22, p. 11-35, 2010.

MIRAGAYA, Ana M. F. O Processo de Inclusão das Mulheres nos Jogos Olímpicos. Rio de Janeiro, 2006. Tese (Doutorado em Educação Física) - Universidade Gama Filho.

MONTANHA, Fausto A. R. Pi. Mídia, Esporte e Idolatria: o Jornal do Brasil e a representação dos atletas brasileiros nos Jogos Olímpicos. Rio de Janeiro, 2014. Dissertação (Mestrado em Comunicação) - Universidade do Estado do Rio de Janeiro.

- Os Jogos Olímpicos na capital da República: narrativas da imprensa e campo esportivo no Rio de Janeiro (1890-1935). Rio de Janeiro, 2018. Tese (Doutorado em Comunicação) - Universidade do Estado do Rio De Janeiro.

MORRIS, Andrew. "To Make the Four Hundred Million Move": The Late Qing Dynasty Origins of Modern Chinese Sport and Physical Culture. Comparative Studies in Society and History. V. 42, n. 4, p. 876-906, 2000.

NASCIMENTO, Paulo H. Mulheres no pódio: as histórias de vida das primeiras medalhistas olímpicas brasileiras. São Paulo, 2012. Dissertação (Mestrado em Educação) - Universidade de São Paulo.

NETO, Marcia F. A participação do Brasil no Movimento Olímpico Internacional no período de 1826 a 1925. Rio de Janeiro, 1999. Tese (Doutorado em Educação Física) Universidade Gama Filho.

NUNES, Alexandre V. A Influência da Imigração Japonesa no Desenvolvimento do Judô Brasileiro: uma genealogia dos atletas brasileiros medalhistas em Jogos Olímpicos e Campeonatos Mundiais. São Paulo, 2011. Tese (Doutorado em Educação Física) Universidade de São Paulo.

RIDER, Toby C.; WAMSLEY, Kevin B. Myth, Heritage and the Olympic Enterprise. In: LENSKYJ, H. J.; WAGG, S. (eds.) The Palgrave Handbook of Olympic Studies. Hampshire/Reino Unido: Macmillan Publishers, 2012, p. 289-303. 
Dossiê | O Brasil e o passado dos Jogos Olímpicos Modernos: um vazio historiográfico (SANTOS, João Manuel Casquinha Malaia; GIGLIO, Sérgio Settani)

ROSINA, Dhenis. Entre narrativas, fragmentos e estilhas: construções de atletas brasileiros sobre os jogos olímpicos do México de 1968. São Paulo, 2018. Tese (Doutorado em Educação Física e Esporte) - Universidade de São Paulo.

RUBIO, Katia. A experiência da pesquisa "Memórias olímpicas por atletas olímpicos brasileiros". Acervo, V. 27, n. 2, p. 93-105, 2014.

SANTOS, Doiara S. Narrativas Identitárias do Nacional nos Jogos Olímpicos de Inverno Vancouver 2010. Vitória, 2011. Dissertação (Mestrado em Educação Física) Universidade Federal do Espírito Santo.

SCHIAVON, Laurita M. Ginástica artística feminina e história oral: a formação desportiva de ginastas brasileiras participantes de Jogos Olímpicos (1980-2004). Campinas, 2009. Tese (Doutorado em Educação Física) - Universidade Estadual de Campinas.

SOUZA, Gabriela C. História do judô feminino no Brasil: da quebra da proibição (1979) à oficialização em olímpiadas (1992). Rio de Janeiro, 2007. Dissertação (Mestrado em Educação Física) - Universidade Gama Filho.

TEIXEIRA, Karoline V. A Orgia dos Sentidos: A construção do corpo nas imagens de Olympia de Leni Riefenstahl. Fortaleza, 2008. Dissertação (Mestrado em História) Universidade Federal do Ceará.

TERRET, Thierry Is There a French Sport History? Reflections on French Sport Historiography. The International Journal of the History of Sport, V. 28, n. 14, p. 20612084, 2011.

VACZI, Mariann; BAIRNER, Alan; WHIGHAM, Stuart. Where extremes meet: Sport, nationalism, and secessionism in Catalonia and Scotland. Nations and Nationalism, p. 117, 2019.

VAREJÃO, Flavia B. Esporte e Relações Internacionais: Análise de não-adesão do Brasil aos boicotes aos Jogos Olímpicos de Moscou (1980) e Los Angeles (1984). Niterói, 2006. Dissertação (Mestrado em Relações Internacionais) - Universidade Federal Fluminense.

WARD, Paul. Britishness since 1870. Londres: Routledge, 2004.

. Last Man Picked. Do Mainstream Historians Need to Play with Sports Historians? The International Journal of the History of Sport, V. 30, n. 1, p. 6-13, 2013.

WIGGINS, David; MASON, Daniel. The socio-historical process in sport studies. In: ANDREWS, David; MASON, Daniel; SILK, Michael (Orgs.). Qualitative methods in sports studies. Nova York: Berg, 2005, p. 39-64.

YOON, Jongsoo Lee Hyunsun. Narratives of the nation in the Olympic opening ceremonies: comparative analysis of Beijing 2008 and London 2012. Nations and Nationalism. p. 1-18, 2017.

YOUNG, Christopher; HILBRENNER, Anke; TOMLINSON, Alan. Source European Sport Historiography: Challenges and Opportunities. Journal of Sport History, V. 38, n. 2, p. 181-187, 2011. 